\title{
O impacto da globalização em São Paulo e a precarização das condições de vida*
}

\begin{abstract}
This work analyses the processes that have recently transformed Sao Paulo from an economic and social point of view. When approaching the impact of reorganising the productive system in the location of activities, it seeks to enhance the understanding of the present determinants in the urban space structuring. For this, it retakes the main constitution phases of Sao Paulo as a metropolis during the XX century. It discusses the present stalemates of the economic modernisation and the deterioration of living conditions.
\end{abstract}

Keywords: globalization, metropolization, Sao Paulo.

\section{Resumo}

O trabalho analisa os processos que vêm transformando, recentemente, São Paulo do ponto de vista econômico e social. Ao abordar o impacto da reorganização do sistema produtivo na localização das atividades industriais e de comercio e serviços, procura avançar no entendimento dos determinantes atuais da estruturação do espaço urbano. Para isso retoma as principais etapas de constituição de São Paulo como metrópole no decorrer do século XX. Discute os impasses atuais da modernização econômica e a precarização das condições de vida.

Palavras-chave: globalizaçao, metropolização, São Paulo. 


\section{A formação da cidade}

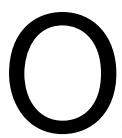
primeiro efeito da expansão da produção cafeeira sobre a cidade de São Paulo, na metade do século XIX, foi ampliar sua função de entreposto comercial. Pela cidade cruzavam-se as rotas comerciais entre o litoral e o interior do Estado de São Paulo, entre o sul e o Rio de Janeiro, capital do país e entre o interior e Mato Grosso.

Apesar do comercio cafeeiro localizar - se sobretudo em Santos, é São Paulo, capital do Estado que vai sediar as matrizes dos estabelecimentos bancários, dependentes, em alto grau, da política econômica do governo. Outro fator próprio da economia cafeeira que tem impacto no desenvolvimento da cidade foi o fato dos fazendeiros de café fixarem residência na cidade. Para eles a comercialização era tão importante quanto a produção. A vinda dos fazendeiros para a cidade representou o loteamento de chácaras e a abertura de novos bairros.

Até a metade do século XIX a cidade de São Paulo está confinada na colina central em posição ligeiramente elevada que garantia a defesa aos ataques. Nesta área, limitada por um lado pelo córrego do Anhangabaú e pelo outro lado pelo Rio Tamanduateí, moravam as elites paulistanas dividindo o espaço com casas de aluguel e cortiços. Alí localizavam-se, também, o comercio de luxo e as grandes casa bancárias.

A expansão do núcleo central se fez em duas direções, para o lado leste, servidos pela ferrovia e separados da colina central pela

\footnotetext{
Professora titular da Faculdade de Arquitetura e Urbanismo da Universidade de São Paulo.Presidente Associação Nacional de Pós Graduação Planejamento Urbano e Regional 2001 2003. E-mail: crisleme@usp.br

Trabalho apresentado como pesquisadora visitante junto ao Japan Center for Area Studies, National Museum of Ethnology, Osaka, Japão, em 2002.
}

várzea inundável do rio Tamanduateí, vão se situar os bairros industriais e de moradia operária e do outro lado em uma área alta, plana e mais saudável irão se localizar os loteamentos de classe de renda mais alta. Estes vetores sinalizam o início do processo de segregação sócio espacial na cidade de São Paulo.

A construção do Viaduto do Chá unindo os dois lados do vale do Anhangabaú possibilitou o deslocamento das atividades comerciais do centro em direção aos bairros de moradia das classes de renda mais alta e resultou em uma bipartição do centro. Na parte nova, alem do Anhangabaú localizam se os escritórios de profissionais liberais, o comercio de luxo, os cinemas, restaurantes dirigidos às classes de renda mais alta. No outro lado do vale, no núcleo histórico, permanecem o comercio e serviços das classes populares. Estudando a lógica deste processo de estruturação do espaço urbano Flavio Villaça (1998) desenvolve a tese sobre a relação entre 0 deslocamento das atividades de comercio e serviços de maior prestígio e das instituições públicas na direção do vetor de desenvolvimento da moradia das classes de renda mais alta.

O processo de deslocamento de atividades se faz com a substituição das edificações térreas e de sobrados. Somekh (1997), ao descrever o processo de verticalização em São Paulo, observa que no período entre a metade da década de 20 e o final da década de 30 ocorre o processo de verticalização, tanto na área do triângulo central, como nos bairros do outro lado do vale do Anhangabaú. Como mostra a autora ,a verticalização até 1939 era um fenômeno tipicamente central e predominantemente terciário, segue-se um período de construção de edifícios predominantemente residenciais localizados nos bairros próximos ao centro.

Nos anos sessenta inicia- se um novo processo de separação e especialização das atividades de comercio e serviços. Confirman- 
do o vetor de expansão em direção sudoeste instalam- se na prestigiosa Avenida Paulista edifícios de escritórios e serviços financeiros ocupando os lotes das residências.

\section{A formação da metrópole}

A correspondência entre a expansão do setor cafeeiro e o nascimento da atividade industrial data do século XIX. A relação de dependência entre os dois setores se manifesta tanto no período de auge da acumulação cafeeira, quando os lucros estavam acima da capacidade de inversão no setor e o capital se desloca para a industria, como, também, nos períodos de baixa, quando a industria se beneficia do declínio das importações, absorvendo a capacidade ociosa e produzindo mais.

Oliveira (1982) observa que quando a "industrialização começa a ser o motor da expansão capitalista no Brasil, ela tem que ser simultaneamente urbana e tem que ser fundamentalmente urbana porque não pode apoiar-se em nenhuma pretérita divisão social do trabalho no interior das unidades agrícolas" (42). Isto significava que as indústrias para a produção de um bem não durável de consumo (o exemplo utilizado pelo autor é a industria Matarazzo) precisavam instalar dentro de si, toda uma complexa divisão social do trabalho, desde a produção de bens de capital até as atividades de apoio à comercialização e distribuição.

Esta concentração de diferentes atividades em uma única unidade industrial exigia, segundo Oliveira, por um lado alto grau de capitalização, o que explicaria a concentração de capital e a tendência à formação de oligopólios e conglomerados e dialéticamente, baixa capacidade de acumulação em função da baixa produtividade do trabalho. A abertura de novos postos de trabalho em função deste processo particular de industrialização atraiu à cidade grandes levas de migrantes .
A industria paulista teve seu grande salto qualitativo entre 1907 e 1919 quando passa a concentrar $31 \%$ da produção nacional. Na década seguinte a mudança será qualitativa diversificando a produção e introduzindo alguns setores mais dinâmicos de bens de produção como a industria de cimento, fabricação de motores elétricos e maquinas têxtil.

A crise do café, em 1929 e a revolução de 30 têm sido consideradas como os marcos da transição da denominada República Velha ou Primeira Republica e o novo regime político que se instala com o golpe militar de Getúlio Vargas em 1937. Dois aspectos destes acontecimentos são importantes para se compreender as relações particulares que se darão ao nível local: a passagem de uma atividade econômica em que o centro dinâmico é a atividade agrícola para exportação, para a atividade industrial e o rompimento da organização política descentralizada, apoiada no alto grau de autonomia dos estados federados em favor do fortalecimento do poder central.

Esta passagem, tanto em termos políticos como econômicos, não pode ser vista, simplesmente, como uma relação de oposição ou complementaridade, mas como uma relação de contradição, que estaria nas próprias origens da formação do capital cafeeiro, na existência de outras atividades, incluindo as indústrias, não diretamente vinculadas à exportação, mas articuladas à expansão da produção cafeeira.

Saes (1986) observa que "a crise de 1929 e a grande depressão dos anos trinta, ao darem a industria posição de crescente importância, vinham, portanto, acentuar e confirmar os rumos do desenvolvimento do capital cafeeiro [...] A partir de então as diversas frações de capital assumem sua própria identidade, as ligações entre frações se tornam tênues, parece possível a partir de 1930, encontrar uma burguesia 'bancária', uma burguesia agrária, uma burguesia comercial" (277). 
A implantação de um Estado forte e centralizado, a partir de 1937, significou de fato, não a exclusão de interesses econômicos dominantes do período anterior, mas sim uma redefinição de canais de acesso e influência com o poder central. Os investimentos do governo federal, nos anos 30 , para o desenvolvimento industrial, resultaram na concentração no Estado de São Paulo da maior parte dos estabelecimentos industriais, da produção e do pessoal ocupado. Neste período, a política de proteção à indústria nacional fazia com que o capital industrial paulista ditasse as regras fortalecendo ainda mais sua hegemonia. $\mathrm{Na}$ década de cinquenta, no governo de Juscelino Kubitschek, uma nova fase da industrialização, destinada a produção de bens de consumo e produção, foi predominantemente dirigida às regiões de maior industrialização. O poder público também concentrou a maior parte dos investimentos em energia elétrica, comunicações e transportes na região Sudeste. Estas políticas consolidaram a posição de liderança do Estado de São Paulo na economia nacional.

Até a década de 50, a distribuição das industrias ao longo das ferrovias no território da cidade de São Paulo apresentava-se de forma diferenciada. A pesquisa realizada pelo escritório SAGMACS em 1957 constatou uma concentração de industrias ao longo da ferrovia que se dirigia a Santos e pequena tanto ao longo da ferrovia que levava ao interior do Estado, como da que ligava São Paulo ao Rio de Janeiro.

Esta situação modifica-se radicalmente com a abertura das modernas rodovias, a partir dos anos cinqüenta, integrando São Paulo ao território nacional. Ao longo da via Anchieta prossegue o desenvolvimento industrial. Ligando São Paulo e os municípios de São Bernardo e Santo André ao porto de Santos instalase um dinâmico setor industrial, incluindo o automobilístico. A integração de São Paulo com os outros Estados do Brasil se faz a partir da ligação com o Rio de Janeiro através da via Dutra. Ao longo desta rodovia localizaram se os setores de ponta da industria nacional, inicialmente o automobilístico, prosseguindo, mais tarde, com a industria eletrônica, aeronáutica e espacial.

\section{Os processos de segregação sócio espacial}

O processo de segregação espacial na cidade de São Paulo por classes sociais que se iniciara no final do século XIX com a abertura dos loteamentos no outro lado do vale do Anhangabaú se acelera com o crescimento da população nas primeiras décadas do século XX. A pequena cidade de 19.000 habitantes em 1870 atinge perto de um milhão de habitantes em 1930

O tipo de industria que se instala em São Paulo neste período, reunindo dentro de si uma complexa divisão social do trabalho, atraiu à cidade grandes levas de migrantes. Novos locais de residência e de localização de indústrias eram constantemente abertos. $\mathrm{O}$ processo de periferização decorre da própria expansão da atividade industrial que cria novos e mais diversificados centros.

A casa alugada, e especialmente o cortiço, foram durante as primeiras décadas do século XX a forma de moradia das classes de renda mais baixa. Com o aumento da população urbana em função do crescimento da atividade industrial surgem novas formas de habitação e que, a nosso ver, concorrem para a transformação na estrutura urbana da cidade de São Paulo: a expansão da área urbanizada e a localização na periferia da cidade, das habitações dos trabalhadores. O aluguel ainda é a forma dominante de acesso à habitação, porém tem início neste período a solução que se tornará cada vez mais difundida e dominante, a partir dos anos 60 , a auto-construção da habitação na periferia da cidade.

Em São Paulo, a localização na periferia da cidade das habitações das classes de renda mais baixa, constatação reafirmada pelos diferentes estudos urbanos está a nosso ver 
relacionada a dois processos: a verticalização do centro com consequente expulsão das residências de classes mais baixas para a periferia e a transformação do sistema de transportes coletivos. No início do século XX os bondes foram a forma de transporte coletivo dominante na cidade. A Light, empresa de capital inglês, concessionária dos serviços de eletricidade e de transporte público atendia preferencialmente os loteamentos de classe alta. Existem registros nos arquivos da empresa de reclamações de industriais não atendidos nas suas reivindicações de extensão de linhas de bondes ao local das fábricas.

A rigidez dos trilhos dos bondes é inicialmente complementada e gradualmente substituída pelo ônibus, estendendo o serviço a áreas não atendidas. A malha viária necessária a esta mudança foi implantada de acordo com os princípios de um sistema viário radial proposto no Plano de Avenidas e implantado nas administrações de Fábio Prado e Prestes Maia no período entre 1934 e1945.

O transporte por ônibus se, por um lado torna possível o deslocamento diário da população, por outro lado, o faz a níveis extremamente precários em termos de tempo de deslocamento, frequência e segurança.

Sem dúvida, muitas das obras viárias realizadas tiveram relação com os loteamentos de classe alta que se abriam nesta época em São Paulo, em especial os da companhia de capital inglês City. Elas estabeleceram novas e mais amplas ligações entre os bairros e o centro da cidade e também integraram os bairros entre si.

A concepção de cidade, implícita nas propostas do Plano de Avenidas de ocupação extensiva do solo estruturada por um sistema viário radial-perimetral, corresponde ao nível da estrutura urbana por um lado ao novo padrão de ocupação periférico da cidade e, por outro lado, garante uma integração mais eficiente entre os diferentes bairros e o centro da cidade. Prepara-se dessa forma uma estrutura urbana mais integrada e homogênea. A realização destas obras no curto espaço de dez anos teve um impacto importante nas condições de mobilidade tanto de mercadorias como de pessoas, condição necessária à expansão do processo de industrialização que ocorrerá nas próximas décadas.

No decorrer do século XX, o padrão de segregação comum às metrópoles brasileiras é o que diferencia o centro da periferia em termos de equipamentos urbanos (água, esgoto, luz, transporte público). Mautner (1995) observa que o significado preciso do conceito social de periferia em São Paulo desvenda o processo histórico de produção do espaço urbano.

Geograficamente significa as franjas da cidade e para a sociologia urbana o local onde moram os pobres. Na medida em que a cidade cresce, por anéis concêntricos, as franjas vão sendo equipadas, melhora a qualidade da habitação produzida em auto construção e novas periferias vão sendo produzidas.

A política habitacional empreendida, a partir dos anos sessenta, com os fundos do Sistema Federal de Habitação reforçou a expansão precária para a periferia. Grandes conjuntos habitacionais foram construídos neste período nas extremidades leste e sul da zona rural do município. Pela legislação de uso e ocupação do solo do município de São Paulo o único uso urbano permitido na zona rural era para a construção de conjuntos habitacionais o que tornou estes terrenos, uma reserva de terras de baixo custo da Companhia municipal de habitação municipal. Entretanto, não tinham infraestrutura de saneamento, transporte público, nem equipamentos de saúde e educação. 
Maria Cristina da Silva Leme

llustração 1: Jardim Ângela, periferia de São Paulo. Foto Antonio Sagese, 2001.

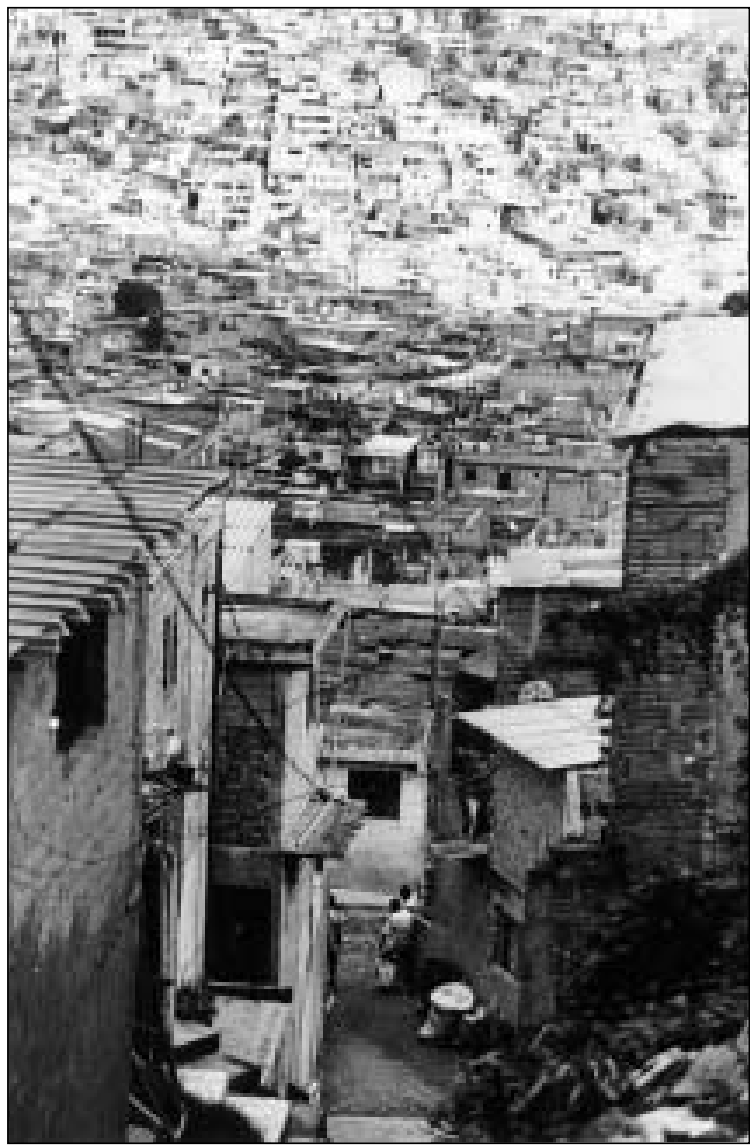

\section{A desconcentração da industria}

As análises apresentadas a seguir estão baseadas na pesquisa "Territorialidades da globalização em São Paulo", coordenada pelo Prof. Antonio Claudio Moreira e que contou com a nossa participação, da Profa. Suzana Pasternak e do Prof. João Sette Whitaker. Realizada em parceria com a Secretaria Municipal de Planejamento de São Paulo no Programa de Políticas Públicas da Fundação de Apoio aa pesquisa do Estado de São Paulo FAPESP, consistiu em investigação de caráter exploratório, sobre as manifestações territoriais do processo de reestruturação econômica na área urbana do município de São Paulo.
Nos anos 70, no período do "milagre econômico" inicia-se um processo de desconcentração da indústria, sem prejuízo da hegemonia paulista. Schiffer (1999) enfatiza o controle desta descentralização pelo capital industrial paulista, visando aumentar a acumulação intensiva e enfraquecer as ações dos sindicatos, cada vez mais fortes na capital de São Paulo. Este novo estágio da industrialização paulista ocorreu em direção ao interior do Estado de São Paulo, complementando a produção da capital paulista. O incremento de infra-estrutura como rede de transporte e capacidade energética, ambos concentrados em São Paulo e seu entorno, permitiram à metrópole gerenciar e reorganizar a 
distribuição das atividades produtivas e da infra-estrutura no território brasileiro.

A partir da abertura comercial, no final da década de oitenta, foram incorporados processos de reestruturação produtiva, mudando-se os paradigmas para conseguir se ajustar à competitividade externa. Estas mudanças provocaram alterações não somente na indústria, mas no comércio, serviços e nas relações sociais. A economia paulista, pela sua complexidade, sofreu grande impacto. Houve uma redução de um terço no emprego industrial no período entre 1989 e 1996. A emigração de plantas produtivas, quando houve, manteve seus centros de decisão e planejamento intimamente ligados à Região Metropolitana de São Paulo. Das novas unidades locais abertas entre 1990 e 1996, 53\% instalaram-se na Região Metropolitana, $46 \%$ no interior do Estado (concentra- das num raio de $100 \mathrm{~km}$ de São Paulo), 18\% em outros estados, $2 \%$ no Mercosul e $1 \%$ em outros países (Martone Branco, 2000).

Martone Branco observa que a maior perda de emprego industrial não foi decorrente de uma diminuição dessa atividade na capital e/ ou região metropolitana, mas sim de sua modernização, com a introdução de novos métodos de organização do trabalho e que foi a estratégia mais adotada no processo de reestruturação alcançando $64,2 \%$ das empresas, que representam $90 \%$ do valor adicionado na indústria paulista. $O$ autor conclui que houve um processo de desindustrialização do emprego, porém não significando redução da atividade industrial e sim um aumento de sua competitividade, acarretando maiores ganhos em sua produtividade.

Figura 1. Distribuição do número de unidades, pessoal ocupado e valor adicionado, do Município de São Paulo, da Região Metropolitana de São Paulo e da Macro-região de São Paulo, em porcentagem sobre o total do Estado de São Paulo - 1996.

\begin{tabular}{|l|c|c|c|}
\hline Região & $\begin{array}{c}\text { Número de } \\
\text { Unidades }\end{array}$ & $\begin{array}{c}\text { Pessoal } \\
\text { Ocupado }\end{array}$ & $\begin{array}{c}\text { Valor } \\
\text { Adicionado }\end{array}$ \\
\hline Município de São Paulo & 40.3 & 33 & 33.1 \\
\hline Região Metropolitana de São Paulo & 56.9 & 56.8 & 60.4 \\
\hline $\begin{array}{l}\text { Regiões de São Paulo, Campinas, } \\
\text { São José dos Campos, Sorocaba e Santos. }\end{array}$ & 82.0 & 85.2 & 90.3 \\
\hline
\end{tabular}

Fonte: Fundação Sistema Estadual de Análise de Dados - Seade. Pesquisa da Atividade Econômica Paulista - PAEP 1996.

\section{O novo parque industrial paulistano}

A análise de dados da PAEP 1996 por Araújo (1999) mostra que as empresas de grande porte (mais de 500 empregados), eram apenas $7,3 \%$ das indústrias paulistanas e respondiam por $58,2 \%$ do valor agregado da industria paulistana. Por sua vez as indústrias de médio porte (mais de 30 ou 20 empregados), eram apenas $10,4 \%$ das industrias paulistanas e respondiam por $24,3 \%$ do valor agregado da indústria paulistana. As pequenas indústrias, $82,3 \%$ das indústrias paulistanas, respondem por $17,5 \%$ do valor agregado das industrias paulistanas.

Segundo ainda os dados da PAEP 1996 , $52 \%$ das unidades industriais instaladas no período 1990 - 1996 localizaram-se na RMSP 
demonstrando que esta Região, apesar de suas deseconomias, ainda é uma boa opção para a localização industrial.

As analises mais recentes realizadas pelo Instituto Florestan Fernandes (2000) apontam para uma mudança nos padrões de localização da indústria em São Paulo. Algumas grandes e médias indústrias deixando a localização junto aos grandes eixos ferroviários e rodoviários (antiga ferrovia Santos-Jundiaí e rodovias Anchieta e Presidente Dutra) e a dispersão de milhares de pequenas indústrias misturando-se com outros usos e ocupando inclusive áreas da periferia. Nas novas territorializações da produção em São Paulo convivem a modernização tecnológica e gerencial das empresas mais capitalizadas, em geral transnacional, e a precarização dos vínculos empregatícios e das condições de trabalho nas micros e pequenas unidades. As grandes indústrias com mais de 500 empregados ou fecham sua fábrica e migram para outras regiões ou reduzem o seu quadro de empregados.

\section{O setor de comercio e serviços}

Na década de 80 o âmbito de atuação da região metropolitana de São Paulo se consolida a nível nacional. A região começa a assumir, também, um papel importante na América do Sul como centro de atividades terciárias.

As referências ao setor terciário requerem especial atenção sob o ponto de vista conceitual e metodológico. A composição de terciário é bastante heterogênea tanto do ponto de vista da produção (tecnologia empregada, relações de trabalho) integração com o sistema produtivo, como da demanda. Importantes esforços para caracterizar a estrutura econômica e tecnológica do setor vem sendo desenvolvidos pelos pesquisadores da Fundação SEADE e do NESUR/UNICAMP, estudos em que nos apoiamos no desenvolvimento da pesquisa.
A estruturação do setor terciário, segundo Araújo (1992) foi determinada pela expansão e diversificação industrial, a partir dos anos 70 , que criou uma demanda intensiva de serviços especializados de produção e a expansão das ocupações de alta qualificação que passaram a demandar importantes serviços pessoais.

Neste período observa-se, também, uma transformação do setor pela absorção de novas tecnologias, principalmente a informática e a microeletrônica. No início da década de 90 a análise da composição setorial da PEA realizada por Araújo (1992) revela que "a distribuição de emprego segundo setor de atividade na região Metropolitana de São Paulo sofreu uma significativa alteração com aumento da participação do terciário e correspondente queda do secundário" (57). Este estudo mostra, ainda, que o setor cresceu nas atividades mais modernas, serviços especializados de apoio à produção - atividades de gerência, planejamento, marketing, propaganda que precisam estar próximos aos centros de decisão das grandes empresas. Também está concentrada na Região Metropolitana parcela expressiva dos equipamentos mais modernos de fluxo de informações.

Um dos efeitos da reestruturação do setor industrial foi a transferência para outros setores tanto de atividades produtivas, como de atividades de apoio à produção. Este processo de terceirização, separando atividades da unidade produtiva, teve importante efeito no aumento e diversificação do setor terciário paulistano. Teve, também, um impacto não desprezível sobre a estrutura de emprego.

Os trabalhadores desempregados e sem possibilidade de retorno ao setor industrial buscaram novas ocupações no setor terciário, ou abriram seus próprios negócios, incrementando tanto o setor secundário (indústria) como o setor terciário (comércio e serviços), ou ampliaram o setor informal da economia. 
O setor informal tem importância crescente no mercado de trabalho urbano. As análises de Lavinas e Nabuco (1992) para diferentes regiões metropolitanas identificam dois padrões de dinâmica do setor. "Um deles se baseia na expansão da industrialização flexível onde empresas externalizam, cada vez mais, algumas funções, em virtude da redução de custos com a força de trabalho (especialmente encargos sociais), sazonalidade no mercado consumidor, baixa rotação do capital em certas fases do processo de produção, etc. Expandem-se, desta forma, pequenas empresas de serviços ou trabalhadores autônomos sem registro formal diretamente ligados aos setores modernos. Esta expansão, por este motivo, coincide com períodos de expansão industrial e configura uma dinâmica pró-cíclica. Estes parecem ser os casos de São Paulo e Belo Horizonte, regiões metropolitanas que, embora registrando nos últimos anos maior formalização do mercado de trabalho do setor industrial, registram também forte dinamismo, com a informalização, em alguns ramos do setor de serviços produtivos" (25).

Uma das consequências da informalização do emprego é a expansão do "comércio de rua". O estudo do Instituto Florestan Fernandes para São Paulo mostra as territorialidades deste comércio evidenciando a formação de corredores de pontos de comércio. Isto significa uma nova territorialidade em face às descrições anteriores do terciário territorialmente organizado em centros secundários de comércio e serviços diversificados.

\section{A reestruturação do setor terciário}

A abertura econômica e a relativa estabilidade monetária na década de 90 têm forte impacto na reestruturação do setor terciário no estado de São Paulo. As estratégias empresariais antes limitadas a uma guerra de preços passam a serem incrementadas pela busca de eficiência e novos serviços ao consumidor. O estudo de Bessa Turpi e Sinder (1999) mostra que "a partir do crescimento das importações, com a oferta de novos produtos, marcas e preços mais competitivos que os similares nacionais, iniciou-se uma dinâmica de transformação das expectativas de consumo e inserção das empresas nos circuitos internacionais de comércio" (104). A reestruturação do setor implicou na introdução de novos métodos gerenciais, terceirização de atividades, eliminação de pontos deficitários, redimensionamento do tamanho de lojas e informatização para gestão dos estoques.

Com base nas informações da PAEP 96 os autores apontam a fragmentação da estrutura do comércio varejista no Estado de São Paulo caracterizada por uma forte concentração de consumo entre os mais ricos e alta dispersão dos gastos entre os mais pobres. Estas características diferenciadas de consumo permitem a convivência de estruturas de comercialização com formas de organização, disponibilidade de capitais e produtividade muito heterogêneas. Tudo isto se reflete no comércio pela existência de circuitos de distribuição diferenciados.

De um lado destacam-se as grandes organizações: hipermercados, redes de magazines e lojas de departamentos populares, e grandes lojas especializadas (material de construção, moveis, etc.). "São empresas com escalas de produção planejadas, sustentadas por investimentos impulsionados por elevada capacidade de capitalização e estruturas de organização operacional e administrativa razoavelmente sofisticadas" (Bessa Turpi \& Sender, 1999: 104).

De outro lado encontram-se as pequenas empresas, que normalmente possuem um único estabelecimento (empresas unilocalizadas), com baixa densidade de capital, formas mais simples de organização, normalmente vinculadas ao mercado consumidor de menor renda. Segundo os dados da PAEP 96, no Estado de São Paulo são 296.296 em- 
presas unilocalizadas que empregam $77 \%$ do pessoal ocupado no setor e se apropriam de $59,5 \%$ da receita total do varejo. O setor das grandes organizações são apenas 596 empresas, que possuem seis ou mais unidades locais, empregam apenas $15,4 \%$ do pessoal ocupado no setor, mas se apropriam de 32,6\% da receita total do varejo.

As grandes estruturas comerciais na década de 70 e 80 localizaram-se na zona sudoeste do município de São Paulo, próximas aos bairros de residência das classes de renda mais alta.

Nos anos noventa esta situação se modifica pela abertura de avenidas, em especial na zona leste, que cria novas acessibilidades a estas áreas e amplia as possibilidades de localização de novos usos tornando- as atrativas ao mercado imobiliário formal. Como conseqüência observa-se a expansão de hipermercados, shoppings centers e novos centros de negócios em outras regiões do Município.

Apesar da predominância dos grandes equipamentos continuar a ser na zona sudoeste, os investimentos em outras partes da cidade como na zona Sul e na zona Leste, onde se implantaram recentemente os shoppings centers Interlagos e Aricanduva. inserem-se em espaços onde o uso comercial e de serviços tradicionais é extremamente disseminado. Os mapas de uso do solo que apresentam a área construída utilizada pelo setor terciário e a localização dos pontos comerciais mostram bem o espraiamento no território desse tipo de uso, junto às áreas residenciais de médio e baixo padrão.

\section{A criação de novas centralidades}

Observa-se que a localização de grandes empreendimentos de comércio e serviços continua a se manifestar de forma diferenciada no espaço intra-urbano. As informações, sobre o lançamento de edifícios de escritórios e hotéis entre 1985 e 2000, evidenciam claramente os arredores da Marginal do Rio Pinheiros como o foco dos maiores investimentos nesse setor. Nessa área, juntamente com a avenida Paulista, concentram-se os edifícios de escritórios com mais de 10000 metros quadrados que avançam cada vez mais para a zona Sul atingindo áreas próximas da represa Guarapiranga.

Eduardo Nobre(2000) estuda a relação entre estes novos empreendimentos e a organização do mercado imobiliário. Entre 1980 e 1998, o estoque de escritórios da Avenida Marginal do Rio Pinheiros pulou de 670 mil para 2,1 milhões de metros quadrados, enquanto que o da Paulista passou de 1 para 1,6 milhões e o do Centro de 2,4 para 2,7 milhões. Isso faz com que a Avenida Marginal hoje represente 33\% do total de estoque útil de escritórios contra $25 \%$ da Paulista e $42 \%$ do Centro.

O crescimento do estoque da Avenida Marginal do Rio Pinheiros foi acompanhado pela ação dos promotores imobiliários no sentido de cooptar possíveis locatários, principalmente entre as grandes empresas. Em 1975 - Centro e a Paulista concentravam a maioria das sedes dessas empresas em São Paulo com $68 \%$ do total $(54 \%$ no Centro e $14 \%$ na Paulista). Em 1998 a Marginal já despontava como a primeira região nessa concentração com $41 \%$ do total, contra $21 \%$ da Paulista, $18 \%$ do Centro e $20 \%$ em outras regiões .

De toda forma a novidade desta nova centralidade é o porte e o tipo de atividade das edificações, bem como o perfil dos empreendedores imobiliários, ambos diferenciados em relação aos da Av. Paulista e do centro tradicional.

É a presença do grande capital imobiliário nos grandes empreendimentos da Marginal do Rio Pinheiros assim como a significativa presença de grandes empresas que induzem a identificação desta área como uma nova centralidade. Neste caso, esta área não seria uma especialização das áreas centrais da 
llustração 2: Edifícios de escritório Avenida Marginal Pinheiros. Foto Lúcio Kowarick, 2003.

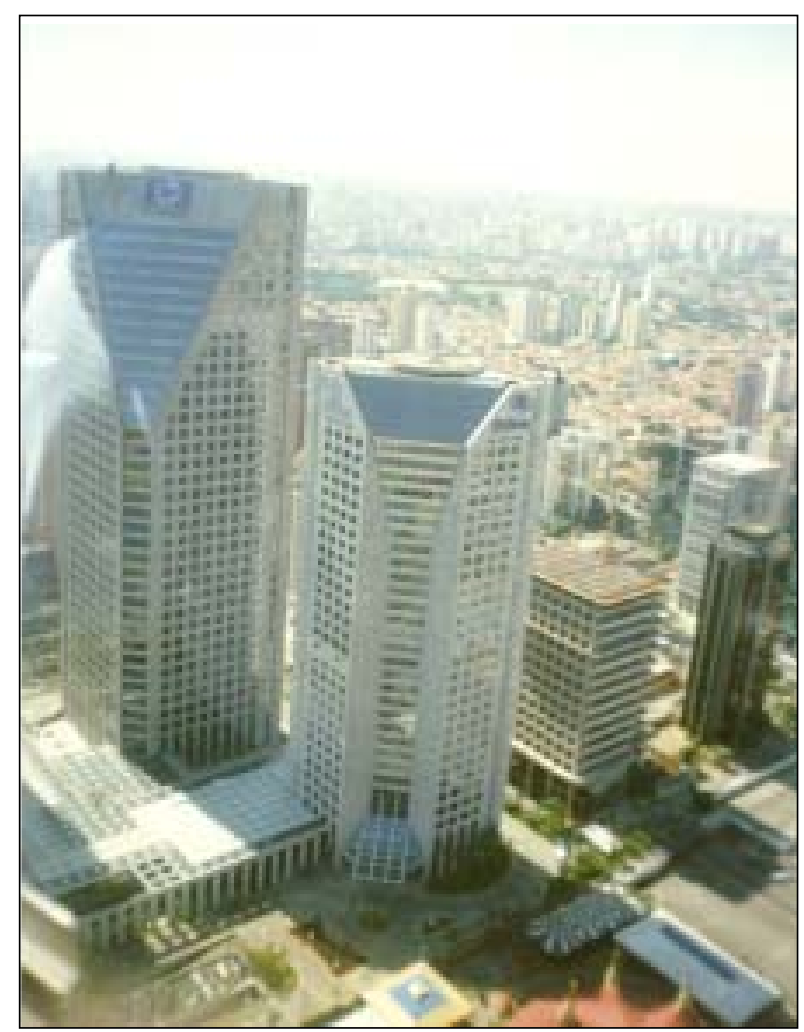

cidade de São Paulo, mas uma nova centralidade, diferenciada das demais centralidades (Centro Tradicional e Av. Paulista) pela presença do "terciário avançado", ou seja, pela presença de aeroportos, TGV, hotéis, centros de convenções, serviços empresariais, universidades, equipamentos culturais, de recreio, esportivos e turísticos específicos para esta nova centralidade, bem como pela disponibilidade de equipamentos de telecomunicações.

Existem controvérsias na interpretação do papel desempenhado pela nova localização de atividades terciárias na estrutura urbana do município de São Paulo. Alguns entendem como a territorialização dos efeitos da globalização da economia em São Paulo. Whitaker Ferreira (2003) considera como uma construção ideológica a idéia de São Paulo cidade global, com grande efetividade para o mercado imobiliário na captação de investimentos públicos em infraestrutura. Em sua tese de doutorado ele procura desmontar o argumento difundido de que a cidade de São Paulo estaria capacitada a alcançar a condição de cidade global como pareceria indicar o surgimento da centralidade da região do vale do Rio Pinheiros. Ele coteja os atributos de cidades globais definidos por estudiosos como Saskia Sassen e Manuel Castells com dados empíricos sobre as atividades econômicas localizadas na cidade de São Paulo e em especial na região do Vale. Mostra que comparada a outras regiões esta não é uma localização privilegiada pelas empresas do que se denomina terciário avançado. 
O que pode se afirmar é que de fato há uma nova territorialidade das atividades que contém as sedes das grandes corporações globalizadas, inclusive instituições financeiras na marginal do Rio Pinheiros. Esta área pode ser entendida como uma especialização das áreas centrais da cidade de São Paulo que vem territorialmente seguindo a localização da população de renda média e alta da cidade, desde o momento em que este centro especializado atravessou o vale do Anhangabaú buscando a Rua Barão de Itapetininga.

\section{Impasses atuais da modernização econômica e precarização das condições de vida}

Os estudos realizados mostraram as consequências da reestruturação produtiva da industria paulista mediante reorganização do trabalho e terceirização. Algumas grandes e médias indústrias deixando a localização junto aos grandes eixos ferroviários e rodoviários e a dispersão das pequenas indústrias misturando-se com outros usos e ocupando inclusive áreas da periferia. Nas novas territorializações da produção em São Paulo convivem a modernização tecnológica e gerencial das empresas mais capitalizadas, em geral transnacional, e a precarização dos vínculos empregatícios e das condições de trabalho nas micros e pequenas unidades.

Observa-se que as indústrias de maior porte estão saindo do território do município. As zonas industriais tradicionais, junto à área central da cidade, onde estavam predominantemente localizadas estas industrias, consistem, hoje, em extensas áreas vazias sujeitas à intensa pressão do mercado imobiliário para mudança de uso do solo.

Os estudos apresentaram, também, as características principais do processo de reestruturação do setor terciário em São Paulo, pela formação de novos empreendimentos gerados pela reestruturação do setor indus- trial, bem como pelos novos empreendimentos gerados, como estratégia de sobrevivência, pelos trabalhadores desempregados pelo processo de reestruturação do setor industrial.

Este processo de crescimento tende a prosseguir, quer pela reestruturação do setor terciário que desenvolve novas centralidades de escala metropolitana, quer pela reestruturação do setor secundário que ainda tem muito a terceirizar.

Observa-se ainda a nova territorialização do comercio e serviços que justapõe grandes shoppings centers, pequenos estabelecimentos de comércio e serviços em assentamentos residenciais populares. Estes estudos confirmam as analises de Bessa, Turpin e Sinder (1999) da existência simultânea de circuitos diferenciados do comércio entre os pouco muito ricos e os muitos mais pobres. A expansão das grandes organizações está limitada, apesar de sua alta produtividade, ao potencial de compra dos poucos mais ricos. As conclusões daquele estudo desenvolvidas para o Estado de São Paulo são aplicáveis também à Capital cuja estrutura sócioeconômica é similar à do Estado.

Este novo processo produz uma nova espacialidade da desigualdade, constituindo uma estrutura em que convivem a fragmentação e a dualização conforme observam Taschner e Bogus (2000) em estudo realizado que revelou a continuação do padrão periférico de crescimento. Analisando a cidade segundo anéis concêntricos as autoras apontam as diferenças de crescimento populacional no interior do município ocorridas nas últimas décadas. A partir dos anos 90 todas as áreas da cidade perderam população com exceção do anel periférico.

A precarização da moradia se acentuou nos anos 90. Os moradores mais pobres são impelidos para regiões cada vez mais distantes, tanto para o entorno da capital como para as cidades limítrofes. A proporção de população favelada na população total vem aumentando 
desde 1991 , de $7,39 \%$ para $8,73 \%$ no ano 2000.

Segundo Taschner e Bogus (2000), o que se percebe é que tanto a localização como o crescimento da população favelada se dá, fundamentalmente, em zonas de preservação ambiental, tanto em zona de mananciais como na região montanhosa ao norte de São Paulo. Este crescimento tem conseqüências cada vez mais sérias tanto sob o ponto de vista das condições de moradia das classes de renda mais baixa, como do ponto de vista ambiental. A ocupação intensiva por favelas às margens das represas Billings e Guarapiranga compromete o uso dos recursos hídricos cada vez mais escassos

Assim podemos concluir que a reestruturação econômica aponta para a dualidade sócio econômica crescente na cidade de São Paulo. É importante observar mudanças qualitativas neste processo. As características físicas da periferia modificaramse nas ultimas décadas e as carências urbanas incidem mais na ausência de equipamentos de educação, saúde, cultura, que possibilitem a inserção desta população no novo mercado de trabalho. Observa- se a proximidade espacial das diferentes classes sociais gerando mudança no padrão de segregação sócio espacial. Caldeira (2000) atribui a construção de barreiras físicas -muros cada vez mais altos- não só por medo da criminalidade mas, também, quando os mais ricos começam a ficar mais perto dos mais pobres, em enclaves nas áreas mais centrais ou quando se localizam em condomínios fechados na periferia.

\section{Referências bibliográficas}

Araújo, M. F. I. (1999). "Mapa da Estrutura Industrial e Comercial do Estado de São Paulo". Revista São Paulo em Perspectiva, 13: 40-52.

(1992). "Uma nova

Centralidade da Região Metropolitana de
São Paulo" Revista São Paulo em Perspectiva, 6, 3: 55-79.

Araújo, T. B. (2000). "Opções Estratégicas e Dinâmica Regional". Revista Brasileira de Estudos Urbanos e Regionais, 2: 9-23.

Bessa, V. C, M. E. Turpin e M. Sinder (1999). "Estrutura econômica e tecnológica do comércio". Revista São Paulo em Perspectiva, 13, 1-2.

Branco, P. P. M., C. Daniel e A. C. Fleury (2001). "Mesa redonda: Desenvolvimento Econômico Local: aliança e competição entre as cidades". Espaço e Debates, 41: 75-95.

Branco, P. P. M. (1999). "Informações e Missão Institucional: pesquisa desvenda economia paulista". Revista São Paulo em Perspectiva, 13: 3-17.

Brasil (República Federativa) (1974). "Projeto de Lei do II Plano Nacional de Desenvolvimento (1975-1979)", Brasília.

Bonduki, N. (1988). "Crise da habitação e a luta pela moradia no pós-guerra". Kowarick, L., As lutas sociais e a cidade São Paulo. São Paulo: Paz e Terra, 95-133.

Caldeira, T. (2000). A cidade dos muros: crime segregação e cidadania em São Paulo. São Paulo: Editora 34.

Kowarick, L. \& C. Ant (1988). "Cem anos de promiscuidade: o cortiço na cidade de São Paulo". Kowarick, L., As lutas sociais e a cidade São Paulo. São Paulo: Paz e Terra, 133-169.

Lavinas,L. \& M. R. Nabuco (1992). "Crise econômica e terciarização no mercado de trabalho". Revista São Paulo em Perspectiva, 6, 3: 25-26.

Lencione, S. \& S. Encione (2001). "Produção no interior, gestão na capital". Pesquisa FAPESP, 61: 72-74.

Mautner, Y. (1999). "A periferia como fronteira de expansão do capital". Schiffer, S. \& C. Déak (org.), O processo de urbanização no Brasil. São Paulo: EDUSP.

Moreira, ${ }^{a}$ C. M. L. (coord.) (2001). "Territorialidades da globalização em São Paulo". Relatório $1^{a}$ fase Programa Políticas Públicas FAPESP. 
Nobre, E. (2000). "Reestruturação econômica e território: expansão recente do terciário na marginal do rio Pinheiros". Tese de doutorado apresentada à Faculdade de Arquitetura e Urbanismo da Universidade de São Paulo. São Paulo: FAUUSP. (2001). "Expansão terciária e novas centralidades nas cidades globais: o caso da Marginal do Rio Pinheiros em São Paulo". Anais do IX Encontro Nacional da ANPUR - Associação Nacional de Pós Graduação e Pesquisa em Planejamento Urbano e Regional.

Oliveira, F. (1982). "O Estado e o urbano". Revista Espaço \& Debates, 6.

Pires Dias, J. M. (coord.) (2000). São Paulo: dinâmicas e transformações. São Paulo: Instituto de Políticas Públicas Florestan Fernandes (CD-ROM).

Rolnik, R. (2000). Reestruturação urbana da metrópole paulistana: análise de territórios em transição. São Paulo: Polis (CD-ROM).

Saes, F. A. M. (1986). A grande empresa de serviços públicos na economia cafeeira. São Paulo: Hucitec.

Santos, M. (1990). "Involução metropolitana e economia segmentada". Ribeiro, C. \& D. Machado (org.), Seminário Metropolização e rede Urbana. Perspectivas dos Anos Noventa. Rio de Janeiro: IPPUR-ANPURCNPq.
São Paulo (Cidade), Secretaria Municipal de Planejamento (2000). "Evolução do Uso do Solo nos Anos 90", São Paulo.

São Paulo, Fundação Sistema Estadual de Análise de Dados - SEADE (1999). Pesquisa da Atividade Econômica Paulista PAEP 1999. São Paulo: SEADE.

Shiffer, S. (1999). "São Paulo como pólo dominante do mercado unificado nacional". Schiffer, S. \& C. Déak (org.), O processo de urbanização no Brasil. São Paulo: EDUSP.

Someck, N. (1997). A (des) verticalização de São Paulo e o urbanismo modernizador. São Paulo: Studio Nobel.

Taschner, S. P. (1995). "Compreendendo a cidade informal". Anais do Seminário Internacional Compreendendo a cidade informal, Belo Horizonte.

Taschner, S. P. \& L. M. M. Bógus (2000). "A cidade dos anéis: São Paulo”. Ribeiro, L. C. de Q. (org.), O futuro das metrópoles desigualdades e governabilidade. Rio de Janeiro: REVAN/FASE.

Villaça, F. (1998). "Espaço intra-urbano no Brasil". São Paulo: Studio Nobel.

\section{FE DE ERRATAS}

En el artículo de Neil Brenner titulado "La formación de la ciudad global y el re-escalamiento del espacio del Estado en la Europa Occidental post-fordista", aparecido en el número 86 de EURE, la Figura 2 fue reproducida con una errata: en la celda inferior izquierda, donde dice "Margen como nodo de acumulación", debe decir "Ciudad como nodo de acumuación". 